\title{
Columellar reconstruction: a refinement of technique
}

\author{
Rotem Tzur, \\ Alexander Bogdanov Berezovsky, \\ Yuval Krieger, \\ Yaron Shoham, \\ Eldad Silberstein
}

Division of Plastic and Reconstructive Surgery, Soroka University Medical Center, BenGurion University of the Negev, Beer-Sheva, Israel

\begin{abstract}
The nose is an important landmark of the face and its shape and beauty is of significant concern. The columella is the subunit between the two nostrils that provides support and projection to the nasal tip and has functional role in nostrils, as well as aesthetic. Ethiology for columellar absence or deficiency is diverse, and it is one of the most complex nasal subunits to reconstruct because of its narrow horizontal dimension, its tenuous vascularity and limited availability of adjacent tissue. We present a patient with columellar, membranous septum and upper lip defect, due to oncological resection. The lip reconstruction was designed using advancement of two upper lip edges with the technique of webster perialar/nasocheek advancement. However, the perialar/nasocheek tissue which is usually discarded was used as inferiorly based skin flaps to reconstruct the membranous septum, columellar skin and nasal vestibule lining. Rib cage cartilage graft was used as columellar strut for support. At 1-year followup, the patient has good nasal contour and projection. Scaring of the columella is very subtle. This is a versatile way for successful reconstruction of a columella and large central facial defect in one-stage operation. It is a method which provides very satisfactory aesthetic result with minimum patient morbidity and discomfort.
\end{abstract}

Keywords: Columella reconstruction / Nose reconstruction / Columella resection

\section{INTRODUCTION}

The nose is an important landmark of the face and its shape and beauty is of significant concern since ancient times. The columella is the subunit between the two nostrils that, along with the lower lateral cartilages and caudal septum, provides support and projection to the nasal tip. It plays a functional role in nostrils patency and nasal breathing [1], and also of major aesthetic significance. Columellar absence or deficiency may occur as a result of tumor resection, bilateral cleft lip, trauma, or cocaine abuse [2-4]. The columella has repeatedly proven to be one of the most complex nasal subunits to reconstruct because of its narrow horizontal dimension, unique contour, its tenuous vascularity and limited availability of adjacent tissue [2]. The need for a reconstruction that will provide the necessary structural and aesthetical proper-

\section{Correspondence: Rotem Tzur}

Division of Plastic and Reconstructive Surgery, Soroka University Medical Center, Ben-

Gurion University of the Negev, Rager 1 BLVD, P.O.B. 151, Beer-Sheva, Israel

E-mail: tsurmd@gmail.com

Received May 13, 2018 / Revised June 7, 2018 / Accepted June 7, 2018 ties of the columella, often necessitates multiple stages. The goal of this paper is to report a case of successful complex one stage columellar reconstruction after oncological resection and to discuss the technique and possible alternatives.

\section{CASE REPORT}

A 75-year-old male patient underwent excision squamous cell carcinoma, arising from his columella (Fig. 1). The resection resulted in a defect involving the whole columella, membranous septum, bilateral aspect of nasal sill, and the medial aspect of upper lip that constituted about $25 \%$ of the upper lip width (Fig. 2). The lip reconstruction was designed using advancement of two upper lip edges with the technique of webster perialar/nasocheek advancement. However, the perialar/nasocheek tissue which is usually discarded was used as inferiorly based skin flaps in a sail shape to reconstruct the membranous septum, columellar skin and nasal vestibule lining (Figs. 3, 4).

The most lateral aspect of the sail-shaped flap was sutured to 
the most inner part of the defect at the nasal floor and septum junction thus creating a pocket. Rib cage cartilage graft was used as columellar strut for support. The cartilage was fixed to the septum remnant with 5-0 PDS suture. The two medial aspects of the nasolabial flaps were sutured together in the midline. Donor site in the nasocheek areas were closed primarily with no remarkable disfigurement (Figs. 5, 6). Postoperative period was uneventful. At 1-year follow-up, the patient has good nasal contour and projection. Scaring of the columella is almost undetectable (Figs. 7,8).

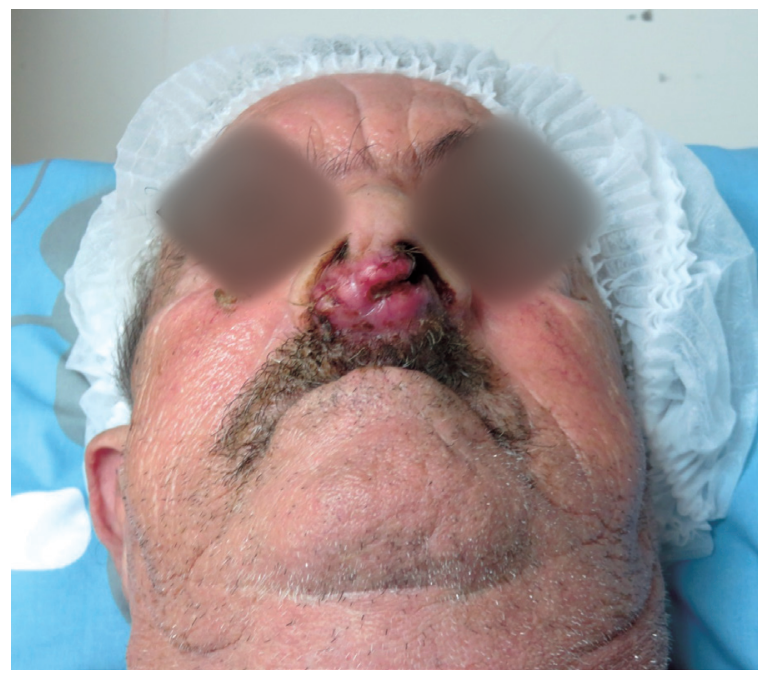

Fig. 1. Squamous cell carcinoma of columella.

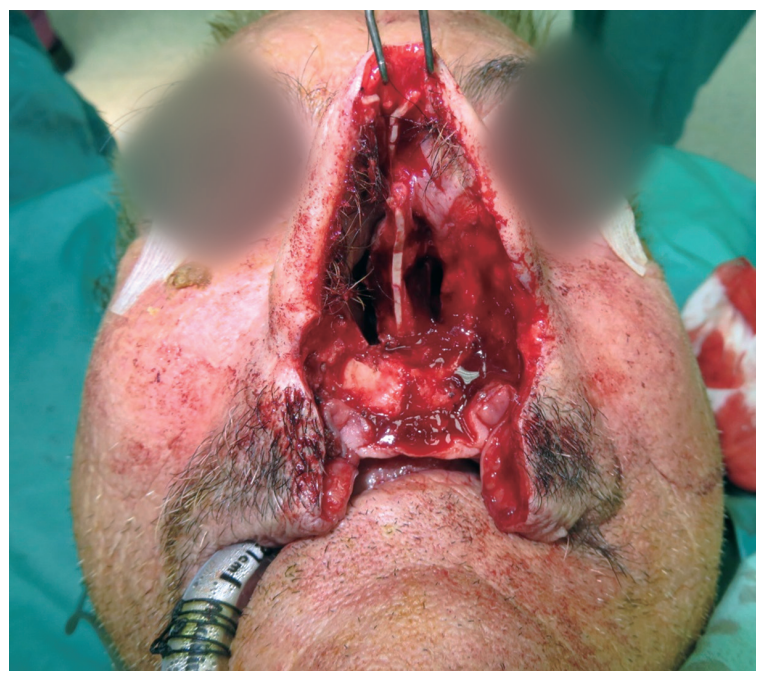

Fig. 2. Defect of columellar, membranous septum and upper lip.

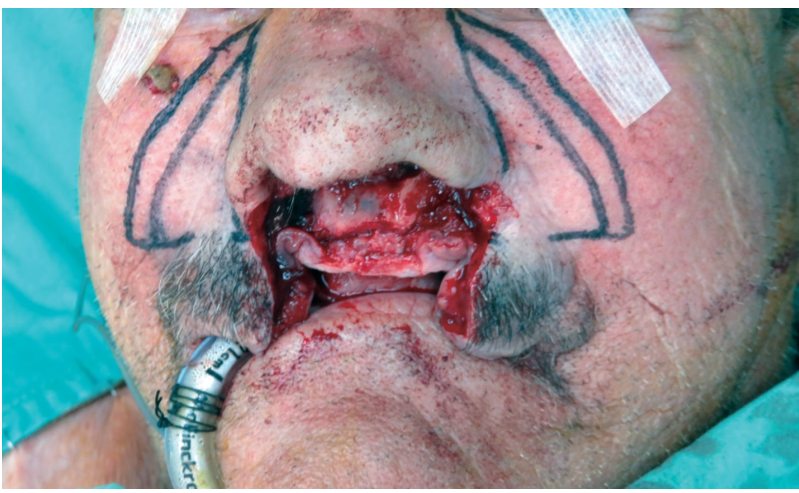

Fig. 3. Planning of inferiorly based sail-shaped flaps.

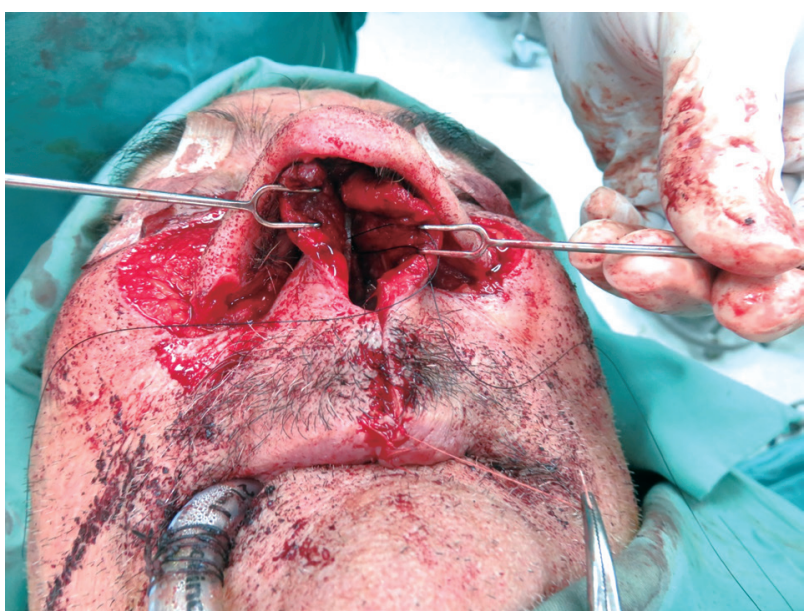

Fig. 4. Sail-shaped flaps brought to reconstruct nasal septum and columella.

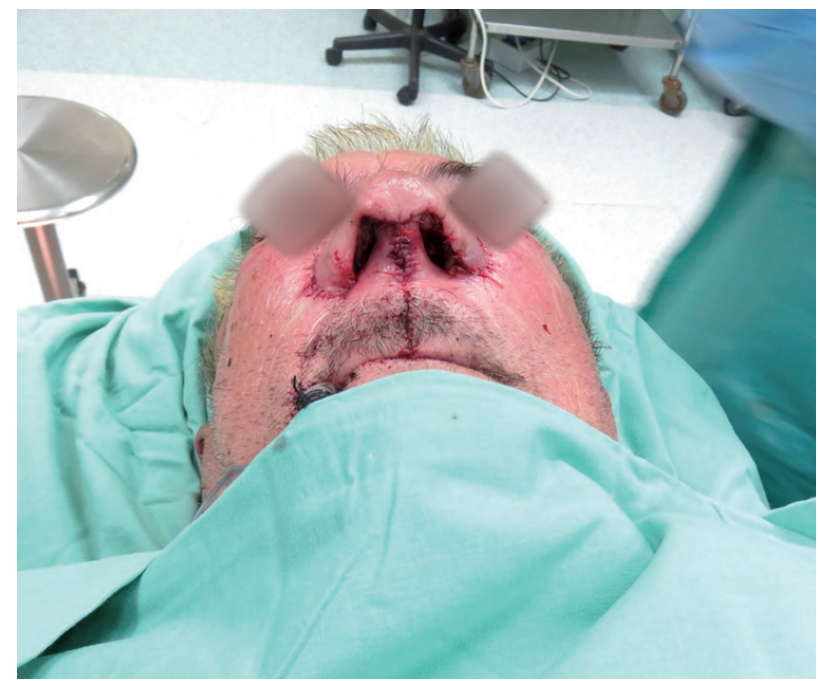

Fig. 5. Postoperative basal view. 


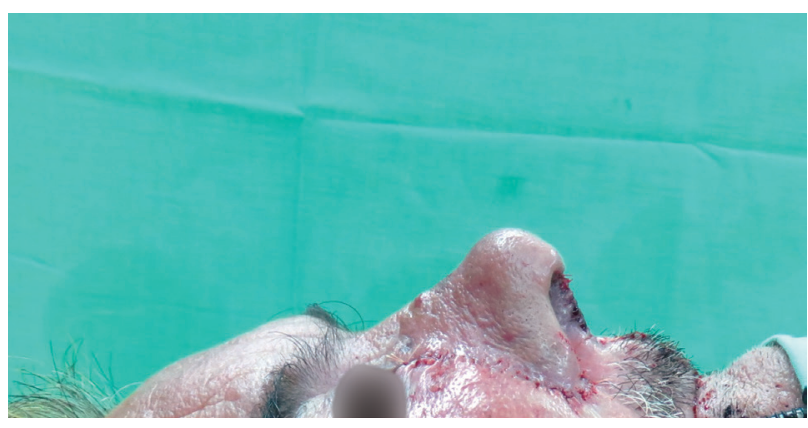

Fig. 6. Postoperative lateral view.

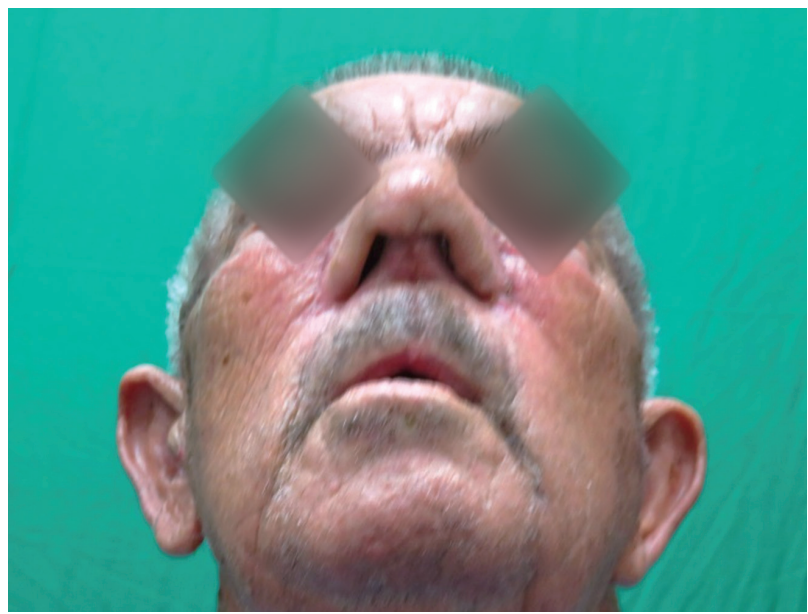

Fig. 7. One-year postoperative basal view.

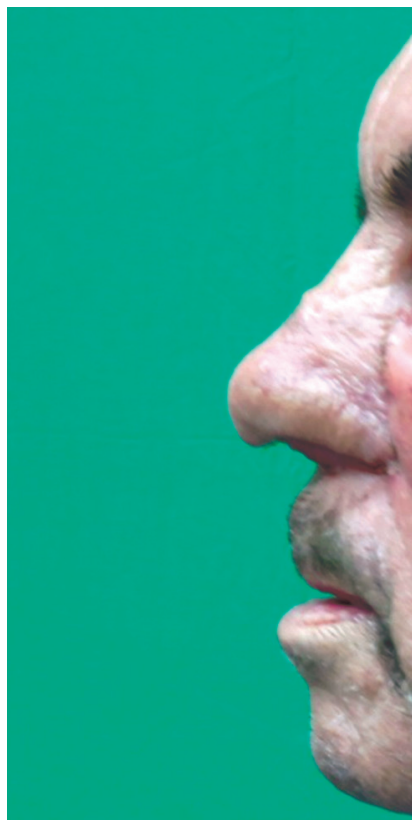

Fig. 8. One-year postoperative lateral view.

\section{DISCUSSION}

Columellar defect or absence may be a result of variety of pathologies. Reconstruction of this delicate central subunit is difficult and challenging because of its narrow horizontal dimension, unique contour, its tenuous vascularity and limited availability of adjacent tissue [2]. Few methods were proposed for this purpose: use of composite grafts $[5,6]$, nasolabial flaps $[7,8]$, nasocheek flaps [9,10], buccal mucosal flap [11], free flap [2], forehead flap [12] and prefabricated flaps [13]. We used nasocheek flaps reconstruction which is a modification of a method described by Akbas et al. [10], which failed to provide sufficient nasal tip support as they discussed. The use of septal cartilage for support as previously described by Jayarajan [9] may not always be available due to the posterior extant of the defect as well as in cases of previous septal surgery or nasal trauma. Some have proposed the use of ear cartilage which is also limited in its amount and strength. The usage of costal cartilage has the advantage of virtually "unlimited" amount as far as nasal reconstruction and is the mechanically stronger. The cones of costal cartilage are donor site scar and higher degree of surgical skills needed for safe harvest.

We described a safe and versatile way for successful reconstruction of a columella and large central facial defect in one-stage operation. It is a method which provides very satisfactory aesthetic result with minimum patient morbidity and discomfort.

\section{CONFLICT OF INTEREST}

No potential conflict of interest relevant to this article was reported.

\section{PATIENT CONSENT}

The patients provided written informed consent for the publication and the use of their images.

\section{REFERENCES}

1. Ayhan M, Sevin A, Aytug Z, Gorgu M, Erdogan B. Reconstruction of congenital and acquired columellar defects: clinical review of 38 pa- 
tients. JCraniofac Surg 2007;18:1500-3.

2. Benito-Ruiz J, Raigosa M, Yoon TS. Columella reconstruction using a free flap from the first web space of the foot. Ann Plast Surg 2012;69:27982.

3. Smith V, Papay FA. Surgical options in columellar reconstruction. Otolaryngol Head Neck Surg 1999;120:947-51.

4. Jayaratne YS, Zwahlen RA, Htun SY, Butow KW. Columella pressure necrosis: a method of surgical reconstruction and its long-term outcome. BMJ Case Rep 2014;2014. pii: bcr2013203132.

5. Teltzrow T, Arens A, Schwipper V. One-stage reconstruction of nasal defects: evaluation of the use of modified auricular composite grafts. Facial Plast Surg 2011;27:243-8.

6. Burm JS. Reconstruction of the nasal tip including the columella and soft triangle using a mastoid composite graft. J Plast Reconstr Aesthet Surg 2006;59:253-6.

7. Ozkus I, Cek DI, Ozkus K. The use of bifid nasolabial flaps in the re- construction of the nose and columella. Ann Plast Surg 1992;29:461-3.

8. Nicolai JP. Reconstruction of the columella with nasolabial flaps. Head Neck Surg 1982;4:374-9.

9. Jayarajan R. Total columella reconstruction using nasocheek flap and septal cartilage graft. Plast Reconstr Surg Glob Open 2015;3:e559.

10. Akbas H, Keskin M, Guneren E, Eroglu L, Demir A. Reconstruction of columella, membranous septum, and upper lip in a single stage operation. Br J Plast Surg 2003;56:291-2.

11. Agrawal KS, Shrotriya R, Pabari M. An innovative technique for columellar reconstruction using 'flip-over' buccal mucosa flap. J Clin Diagn Res 2016;10:PD05-6.

12. Baker SR, Swanson NA. Oblique forehead flap for total reconstruction of the nasal tip and columella. Arch Otolaryngol 1985;111:425-9.

13. Gucer T. Retroauricular prefabricated chondrofasciocutaneous flap for reconstruction of the columella. Plast Reconstr Surg 2002;109:1090-3. 